\title{
Perfil e percepções dos feirantes em relação a feira livre dos municípios de São Pedro do Sul (RS) e Santo Augusto (RS)
}

Profile and perceptions regarding the open street market of municipalities of São Pedro do Sul (RS) and Santo Augusto (RS).

\author{
Gustavo Pinto da Silva', Julio Cesar Paris², Tarcísio Samborski', Andrea Cristina Döor ${ }^{3}$ \\ 'Doutorando do Programa de Pós-Graduação em Extensão Rural da Universidade Federal de Santa Maria. \\ ${ }^{2}$ Mestrando do Programa de Pós-Graduação em Extensão Rural da Universidade Federal de Santa Maria. \\ ${ }^{3}$ Professora do Programa de Pós-Graduação em Extensão Rural da Universidade Federal de Santa Maria
}

\section{Resumo}

O objetivo deste estudo foi identificar e compreender como se manifestam as cadeias curtas de abastecimento através das feiras livres, as relações com outros mercados, o perfil socioeconômico e percepções dos feirantes em relação a feira e sua participação em São Pedro do Sul (RS) e Santo Augusto (RS). A coleta de dados ocorreu no mês de outubro de 2013 por meio da técnica de entrevista estruturada. A tabulação e análise dos dados foi realizada através do software SPSS Statistics Versão 22.0. Os resultados mostram que os feirantes possuem idade média de 39,5 anos em Santo Augusto e 55,45 anos em São Pedro do Sul. A maioria utiliza mão de obra familiar e uma área média de produção de 12,75 hectares em São Pedro do Sul e 10,17 hectares em Santo Augusto. Além da feira livre os agricultores possuem outras formas de participação nos mercados, mas caracterizadas como de cadeias curtas de abastecimento. Verificou-se que os feirantes valorizam atributos diferentes tanto em relação a condição geral da feira livre, como em relação ao seu próprio preparo para a participação nesses espaços de comercialização. Conclui-se que há similitudes no aspecto organizacional entre as feiras, são empreendimentos familiares que apresentam dificuldades de sucessão e possibilitaram o acesso dessas famílias a comercialização e o aprendizado para conquistarem outros mercados.

Palavras-chave: Cadeias curtas de abastecimento, feira livre, alimentação, agricultura familiar.

\begin{abstract}
The aim of this study was to identify and understand how short supply chain manifest open street markets, the relations with other farmers , the socioeconomic profile of farmers and perceptions regarding the fair and its participation in São Pedro do Sul (RS) and Santo Augusto (RS). Data collection occurred in October 2012 from the structured interview technique. The tabulation and analysis of data were performed using SPSS Statistics software version 22.0. The farmers were an average 39.5 years old in Santo Augusto and 55.45 years old in San Pedro do Sul. Most use family labor and an average production area of 12.75 hectares in São Pedro do Sul and 10,17 hectares in Santo Augusto. Besides the open street market, farmers also have other forms of market participation, but characterized as short supply chains. It was found that the farmers value different attributes regarding both the general condition of the open street market, as in relation to preparation of farmers for participation in these commercialization spaces.
\end{abstract}

Keywords: Short chain of supply, open street market, feeding, family farming. 


\section{INTRODUÇÃO}

A mudança no sistema agroalimentar desde a modernização da agricultura gerou profundas transformações na relação entre o consumo e a agricultura. Os consumidores se distanciam dos agricultores, os alimentos chegam através de empresas atravessadoras (ILBERY, 2005). Muitas vezes com perda da qualidade organoléptica e diversidade, ocorre a geração de incerteza e desconfiança por parte dos consumidores (WISKERKE, 2009).

Os mercados baseados em cadeias curtas, mesmo não sendo uma novidade, tem se apresentado como uma alternativa ao padrão hegemônico de abastecimento. Os alimentos comercializados através dessas cadeias são, segundo Renting, Marsden e Banks (2003), carregados de uma quantidade significativa de informações e de valores, capaz de fazer com que o consumidor possa ter juízo sobre sua conveniência, baseado em seu próprio conhecimento, experiência ou imaginário. Elas possuem a capacidade de ressocializar ou repatriar alimentos, carregando consigo uma imagem da origem e o local onde são produzidas, e restabelecem uma relação entre agricultor e consumidor, comunicada pela embalagem ou diretamente através do varejo (MARSDEN; BANKS; BRISTOW, 2000).

O mérito dessa abordagem encontra-se em resgatar a sinergia a partir de especificidades locais das comunidades, da riqueza sociocultural, das identidades dos povos, da tradição das famílias, e de ligar consumidores e agricultores, numa dinâmica que tende a reverter valores para quem está envolvido diretamente nos processos de produção. Esses elementos fortalecem a discussão do desenvolvimento rural, evidenciando um conjunto de oportunidades para a agricultura familiar, podendo se caracterizar um contraponto desses segmentos a conjuntura da globalização e do capitalismo. Segundo Wilkinson (2008), a pequenez da agricultura familiar, quando associada à tradição, natureza, ao artesanal e ao local, se torna uma vantagem estratégica, como um prêmio pelo mercado.

Entre as mais expressivas formas de cadeia curta encontram-se as feiras livres, caracterizadas pela venda direta aos consumidores. Segundo Mazoyer e Roudart (2010) na medida em que as trocas ganharam importância às feiras desenvolveram-se principalmente em cidades e vilarejos. Nelas, os agricultores têm facilidade no processo de troca, liquidez imediata, agregação de valor, além de um contínuo processo de aprendizagem, estabelecido na interação com quem consome os produtos. Para os consumidores, permitem acesso a alimentos frescos, saudáveis, de procedência conhecida, de modo que saibam mais sobre o que consomem, como e por quem é produzido.

Nas feiras, a relação entre agricultores e consumidores assume um papel ativo, em que de acordo com Goodman (2003), os consumidores são parceiros relacionais na transformação das práticas agro-alimentares. Mais do que um espaço de comercialização, configura-se como um espaço simbólico de encontro, onde laços de confiança e amizade passam a ser concretizados entre as partes (PALM, 2013). Para Sabourin (2011), as situações de contato direto dão lugar a relações humanas (conversas e explicações em torno do produto, do trabalho, dos procedimentos, das receitas) as quais geram sentimentos e valores de amizade, de fidelidade e de confiança.

A participação nesses espaços de comercialização oportuniza resistência dos agricultores ao modelo hegemônico de fazer agricultura, além de marcar um conjunto de estratégias e oportunidades passíveis de ampliação para a Agricultura Familiar. Conhecer melhor essas situações propicia conhecimentos para aprimorar a intervenção de agentes do desenvolvimento rural, planejar políticas públicas e compreender o papel da extensão. Interessa, nesse aspecto, saber em que medida uma similitude étnica e cultural entre regiões, contrastada com as diferenças ambientais e de padrão de produção agrícola influencia na expressão das cadeias curtas de abastecimento? Existem diferenças ou semelhanças?

Assim, o trabalho tem por objetivo identificar e compreender como se manifestam as cadeias curtas de abastecimento através das feiras livres, as relações com outros mercados, o perfil socioeconômico e percepções dos feirantes em relação à feira e sua atuação em São Pedro do Sul (RS) e Santo Augusto (RS). O comparativo entre as experiências da atenção ao estudo das feiras livres a partir da percepção do agricultor, suprindo uma carência de publicações nessa perspectiva.

A escolha dos locais de pesquisa, mesmo havendo diferenças ambientais, se deu em função de que a história de ocupação desses municípios é similar e marcada pela imigração europeia e o predomínio de descendentes da agricultura familiar. De um lado São Pedro do Sul, localizado na Depressão Central do Rio Grande do Sul, população total de 16.368 habitantes, dos quais 4.439 são residentes rurais. Suas principais atividades são o arroz, a soja, a pecuária de corte, além de uma ampla diversidade de cultivos próprios da agricultura familiar. Em relação aos processos de modernização da Agricultura, a dificuldade 
imposta pela topografia ondulada e solos arenosos, tem tornando-a bastante tardia, ocorrendo de forma mais pronunciada a partir da valorização da soja, depois dos anos 2000.

Por outro lado Santo Augusto localiza-se na Região Noroeste Colonial do Rio Grande do Sul, com uma população total de 13.968 habitantes, sendo que apresenta uma população rural de 2.588 habitantes. Trata-se de um município formado pela colonização tardia1 de filhos e filhas das colônias velhas de Jaguari e Santa Maria, mesma região de São Pedro do Sul, principalmente de base italiana e polonesa. A soja, milho e trigo são os principais cultivos, seguidos da produção leiteira. Os solos argilosos e profundos, a topografia ondulada e as inovações trazidas pela modernização (mecanização e insumos químicos) permitiram a transformação dos campos nativos em lavouras. Essas mudanças associada à criação de estruturas cooperativas de comercialização alterou a agricultura local, de uma base de produção de alimentos para a integração aos mercados de commodities.

\section{METODOLOGIA}

Os procedimentos de pesquisa foram realizados no segundo semestre de 2013. A pesquisa foi orientada a partir de técnicas de pesquisa qualitativa e quantitativa, em dois momentos diferentes, um primeiro de natureza exploratória e outro descritivo. A parte exploratória compreendeu a utilização de técnicas qualitativas, que segundo Gil (1999), são capazes de proporcionar uma visão geral acerca de um determinado fato, no caso o histórico das feiras livres. Nessa fase optou-se pela entrevista não dirigida, a partir da qual se buscavam estimular os entrevistados para tratarem livremente da evolução das feiras. Este tipo de entrevista, mesmo havendo o risco do entrevistador não eliminar totalmente a pré-estruturação do discurso do entrevistado, apresenta algumas vantagens: o entrevistado pode se manifestar por próprias categorias e linguagens; permite enriquecer o material de análise e de pesquisa, favorecendo a emergência de novas dimensões; oferece a possibilidade de explorar em profundidade as diferentes facetas da experiência do entrevistado; e, permite que incorpore elementos

\footnotetext{
1 Migração interna de filhos ou famílias de imigrantes das primeiras colônias do Estado do Rio Grande do Sul que se situavam na região da Serra, Centro, Vale do Sinos e Paranhana. Esses colonos ocuparam predominantemente a região das matas, porque as áreas de campo nativo estavam sob posse dos fazendeiros e eram locais com severas limitações para a produção, especialmente a acidez dos solos e a alta infestação de formigas cortadeiras (PESAVENTO, 1992).
}

de sua vida, estabelecendo ligações úteis (Poupart, 2010). As entrevistas foram gravadas para posterior transcrição, agrupamentos e análise.

A segunda parte buscou um aprofundamento em torno da principal pergunta orientadora da pesquisa, considerada como de natureza quantitativa. Este tipo de pesquisa é compreendida, segundo Dalfovo et al (2008), como aquela em que a utilização de recursos e técnicas baseadas em análises estatísticas permite a mensuração de fatores com maior precisão, descobrir e classificar as relações entre distintas variáveis e fazer relações de causalidade entre eventos. Para tanto, o instrumento de coleta de dados foi a entrevista estruturada composta por 38 questões seguindo a recomendação de Gil (2009), uma relação fixa de perguntas, cuja ordem e redação deve permanecer invariável para todos os entrevistados. Parte das questões, aquelas que se buscavam medir a intensidade das opiniões dos entrevistados, foi organizada através da escala social de Likert.

Antes da aplicação da entrevista aos atores envolvidos foi tomado o cuidado de avaliar a completude do instrumento de coleta de dados, o grau de aceitação e a capacidade de compreensão. A coleta foi realizada na semana entre 01 e 15 de outubro, diretamente ao feirante no transcorrer da feira livre, buscando criar uma atmosfera de cordialidade e simpatia com os entrevistados, como pressupõe Gil (2009).

Para a tabulação e análises dos dados foi utilizado o software SPSS Statistics Versão 22.0, conforme evidencia Bruni (2012). Um dos primeiros passos para compreender o comportamento das variáveis em termos de elementos observados foi a distribuição de frequências e a utilização de medidas percentuais. Além desse tipo de análise também foi utilizado medidas de variabilidade e outros cruzamentos.

\section{RESULTADOS E DISCUSSÕES}

\section{I Evolução histórica das feiras}

A Feira do Produtor de São Pedro do Sul (RS)

A Feira teve início no ano de 1982, a partir de quatro famílias de feirantes, em conjunto com a EMATER/RS-ASCAR e outros órgãos do setor agropecuário. A Prefeitura disponibilizou um terreno em área central da cidade, onde foram construídas bancas de madeiras para comercialização. Tratava-se de um grupo informal de agricultores, regulados por normas e com a presença de um "Fiscal", um servidor público com a função de 
auxiliar na organização, definição de preços e funcionamento da feira.

A ênfase na qualidade começa a partir de 1986, movida pela constatação de insatisfação de alguns consumidores. No ano de 1989, a empresa de assistência técnica e extensão rural fomenta uma série de procedimentos e ações que visavam estabelecer a qualificação dos feirantes, a organização da produção e a autogestão do grupo, culminando com a fundação da Associação de Feirantes de São Pedro do Sul em 12 de julho do mesmo ano. Entre as melhorias na infra-estrutura da feira, realizadas entre 1990 e 2005, destacam-se a construção de cinco Box, reforma no prédio, e aquisição de utensílios, máquinas e equipamentos.

A Feira funcionou em dois dias por semana até 1999, quando expande para três vezes por semana, incluindo os sábados. Em épocas de excesso de produção ou datas festivas, ocorrem feiras especiais como a Feira da Laranja, da Uva, do Mel, da Flor, da Mandioca, do Peixe, do Milho, do Tomate, entre outras. A extensão rural é evidenciada pelos agricultores, tanto no acompanhamento da comercialização, como na produção ao nível de propriedades.

Atualmente, os cinco Box encontram-se ocupados por 11 famílias, que além dos vínculos com os mercados, também desenvolvem ações sociais, confraternizações e participação em atividades cívicas do município.

\section{A Feira do Produtor de Santo Augusto (RS)}

A feira do produtor no município de Santo Augusto teve seu início oficial no dia 6 de julho de 1993, fruto de um processo de mobilização e organização no ano anterior realizado pelo escritório municipal da EMATER/RS-ASCAR, a Prefeitura Municipal e as famílias de agricultores. Iniciou em boxes de madeira construídos na praça municipal Pompílio Silva. Os feirantes eram cadastrados junto à Secretaria da Saúde e Meio Ambiente, a qual realizava o controle da qualidade dos produtos oferecidos à população. Eram supervisionados por uma comissão composta por seis representantes, que representavam a EMATER/ RS-ASCAR, a Prefeitura, a Secretaria da Saúde, a Secretaria do Desenvolvimento Econômico e os feirantes na época.

Em 25 de março de 1999 foi alugado um prédio na Avenida Central para abrigar a feira, que contava com 34 agricultores inscritos e cadastrados para participar da denominada Colônia Feira do Produtor. Em função de interesses divergentes, em 2005 houve divisão no grupo dos feirantes, criando duas feiras diferentes de agricultores de hortigranjeiros, massas e artesanatos. A Feira Produtos da Terra conta com cinco famílias produtoras de hortigranjeiros. A Colônia Feira do Produtor conta com três famílias responsáveis pela produção diversificada oferecida na feira. As demais famílias dão suporte com a produção de produtos coloniais, massas, doces e artesanatos.

\subsection{Caracterização dos feirantes}

Uma característica comum aos entrevistados é a base familiar de produção, pois não há agricultor empresarial individual entre os feirantes. Considerando que a maioria participa das feiras há mais de 15 anos, destaca-se que não há diferenciação entre os agricultores no sentido de permitir que um deles se torne um agricultor empresarial ou mesmo que tenha ocorrido a entrada de outro

Tabela 01: Sexo, Idade e Escolaridade dos Feirantes das Feiras Livres de São Pedro do Sul (RS) e Santo Augusto (RS).

\begin{tabular}{llcc}
\hline \multirow{2}{*}{ Variável } & & \multicolumn{2}{c}{ Município } \\
\cline { 3 - 4 } Sexo & Masculino & São Pedro do Sul & Santo Augusto \\
& Feminino & $8(72,7 \%)$ & $3(27,3 \%)$ \\
& $\geq$ a 20 anos & $1(14,3 \%)$ & $6(85,7 \%)$ \\
\hline \multirow{5}{*}{ Idade } & Entre 21 e 30 anos & - & $1(14,3 \%)$ \\
& Entre 31 e 40 anos & - & $1(14,3 \%)$ \\
& Entre 41 e 50 anos & $3(27,3 \%)$ & $1(14,3 \%)$ \\
& Entre 51 e 60 anos & $3(27,3 \%)$ & $2(28,6 \%)$ \\
& Mais de 60 anos & $4(36,4 \%)$ & $2(28,6 \%)$ \\
\multirow{5}{*}{ Escolaridade } & $8(72,7 \%)$ & - \\
& $1^{\circ}$ Grau Incompleto & - & $4(57,1 \%)$ \\
& $1^{\circ}$ Grau Completo & $2(18,2 \%)$ & $2(28,6 \%)$ \\
& $2^{\circ}$ Grau Incompleto & $1(9,1 \%)$ & - \\
& $2^{\circ}$ Grau Completo & - & - \\
& Superior incompleto & & $1(14,3 \%)$ \\
\hline
\end{tabular}


agricultor empresarial, provindo da cadeia de abastecimento.

As famílias são compostas em média por 3,59 pessoas. A idade média do responsável pela feira é de 39,5 anos em Santo Augusto e de 55,45 anos em São Pedro do Sul. Em São Pedro do Sul predominam os homens $(72,7 \%)$ como responsáveis pela comercialização, enquanto, em Santo Augusto as mulheres têm uma participação de 85,7 $\%$, conforme detalha a Tabela 01. Pode-se afirmar que é estatisticamente significativa a diferença entre a média de tempo de participação na feira e o sexo do feirante em nível de $90 \%$. A escolaridade dos feirantes é baixa, pois em São Pedro do Sul, $72,7 \%$ dos entrevistados possuem o fundamental incompleto, enquanto em Santo Augusto são $57,1 \%$ com esse nível de escolaridade. Apenas 9,1 $\%$ em São Pedro do Sul e 14,3\% em Santo Augusto possuem o ensino médio completo.

A maioria das famílias, 63,6 \% em São Pedro do Sul e $100 \%$ em Santo Augusto, possuem terra própria, com uma média de 12,75 hectares e de 10,17 hectares, respectivamente. Essa terra é explorada somente por mão de obra familiar em $100 \%$ das propriedades de São Pedro do Sul, como demonstra a Tabela 02, mas em Santo Augusto a situação se inverte, pois apenas $28,6 \%$ das propriedades utiliza exclusivamente a mão de obra familiar. O restante conjuga a utilização de mão de obra da família com a contratação de outros trabalhadores. Pode-se inferir que a maioria dos agricultores tem a base de produção na olericultura, pois $63,6 \%$ produzem folhosas em São Pedro do Sul, e 71,4\% em Santo Augusto.

O padrão tecnológico é marcado pela pre- sença do cultivo protegido em $54,5 \%$ das propriedades em São Pedro do Sul e em 85,8\% em Santo Augusto. A irrigação é outro componente importante, com uma presença de 63,6 \% em São Pedro do Sul e 85,8\% em Santo Augusto. Já a mecanização tem uma presença mais modesta em Santo Augusto com apenas $42,9 \%$ e mantém os mesmos 63,6\% em São Pedro do Sul.

Observa-se que na origem das feiras, os feirantes eram famílias composta por jovens rurais, com baixa escolarização e que buscavam alternativa de produção. Essa afirmação baseia-se em que a idade média do responsável pela feira é de 39,5 anos em Santo Augusto e de 55,45 anos em São Pedro do Sul, frente a uma média de 18 anos de participação nesses espaços de venda. Aparentemente, apesar de melhoria na renda, não houve aumento dos níveis de escolaridade.

A participação da extensão rural oficial através da EMATER/RS-ASCAR foi a principal responsável pela motivação e apoio inicial aos feirantes para os dois casos estudados. A entrada da assistência técnica privada ocorreu nos últimos anos em Santo Augusto devido a especialização e intensificação técnica na área de olericultura, fato concomitante ao término do atendimento aos feirantes pela assistência técnica e extensão rural pública. Mesmo assim, afirma-se que nesses municípios, esta realiza ações que vão além do aspecto da mudança tecnológica da agricultura, pois comporta outras dimensões, tais como a organização dos espaços das feiras, a qualificação para o atendimento aos consumidores, o acesso a políticas públicas, além de outras ações voltadas ao desenvolvimento rural.

Tabela 02: Posse da Terra, Mão de Obra e Tipo de Tecnologia utilizada pelos Feirantes das Feiras Livres de São Pedro do Sul (RS) e Santo Augusto (RS)

\begin{tabular}{llcc}
\hline \multirow{2}{*}{ Variável } & & \multicolumn{2}{c}{ Município } \\
\cline { 3 - 4 } & & São Pedro do Sul & Santo Augusto \\
\hline \multirow{2}{*}{$\begin{array}{l}\text { Posse da } \\
\text { Terra }\end{array}$} & Própria & $7(63,6 \%)$ & $7(100,0 \%)$ \\
& Arrendada & $2(18,2 \%)$ & - \\
\hline \multirow{2}{*}{ Tipo de Mão } & Somente Familiar & $2(18,2 \%)$ & - \\
de Obra & Familiar e Contratada & $7(100 \%)$ & $2(28,6 \%)$ \\
& Familiar e Diarista & - & $2(28,6 \%)$ \\
\hline \multirow{2}{*}{ Tipo de } & Mecanização e irrigação & - & $342,9 \%)$ \\
Tecnologia & Mecanização, irrigação e cultivo & $6(54,5 \%)$ & - \\
Utilizada & protegido & & $3(42,9 \%)$ \\
& Cultivo protegido e irrigação & - & $3(42,9 \%)$ \\
& Não se aplica & $4(36,4 \%)$ & $1(14,3 \%)$ \\
\hline
\end{tabular}


Tabela 03: Perspectiva de sucessão na atividade de Feirante nas Feiras Livres de São Pedro do Sul (RS) e Santo Augusto (RS).

\begin{tabular}{llcc}
\hline \multirow{2}{*}{ Variável } & & \multicolumn{2}{c}{ Município } \\
\cline { 3 - 4 } & Não pensaram no assunto & $4(36,4)$ & Santo Augusto \\
\hline \multirow{5}{*}{ Sucessão } & $\begin{array}{l}\text { Intenção de continuar e } \\
\text { ampliar }\end{array}$ & - & $3(42,9)$ \\
& Perspectiva de continuidade & $4(36,4)$ & $1(14,3)$ \\
& Não tem perspectiva de & $3(27,3)$ & $3(42,9)$ \\
& continuidade & & \\
\hline
\end{tabular}

Em relação à sucessão das famílias nas feiras nos municípios, aplicando o teste do Quiquadrado, pode-se perceber que existe associação estatisticamente significativa entre essas variáveis ao nível de $5 \%$ de significância. Conforme Tabela 03, para o caso de São Pedro do Sul, 36,4\% ainda não pensaram no assunto, $36,4 \%$ espera que alguém da família dê continuidade e 27,3\% não tem ninguém na família pretenso a participar da feira livre. Em Santo Augusto, 42,9\% tem a intenção de continuar e ampliar a participação na feira livre, $14,3 \%$ apresenta sucessão e $42,9 \%$ não existe integrante na família proposto a dar continuidade. Ao analisar a relação da sucessão com ao tipo de assistência técnica recebida, não se verifica associação estatística ao nível de 5\% entre essas variáveis.

\subsection{A feira e os outros mercados da cadeia curta}

A participação dos agricultores nos mercados de cadeia curta acontece a partir da feira livre como forma principal, entretanto ela é exclusiva apenas para $27,3 \%$ dos feirantes de São Pedro do Sul. A maioria (72,7\%), assim como todos aqueles de Santo Augusto apresentam outras opções de relação com os mercados através das cadeias curtas.

Seguindo os diferentes mecanismos propostos por Renting, Marsden e Banks (2003), pode-se constatar que a participação na feira cria outras formas de interação com os mercados. Entre aqueles que a relação se mantém face a face, como a feira livre, em que a confiança e a autenticidade

Gráfico 01: Opções de comercialização dos Feirantes de São Pedro do Sul (RS), em outros canais de cadeia curta após a participação na feira livre (\%).

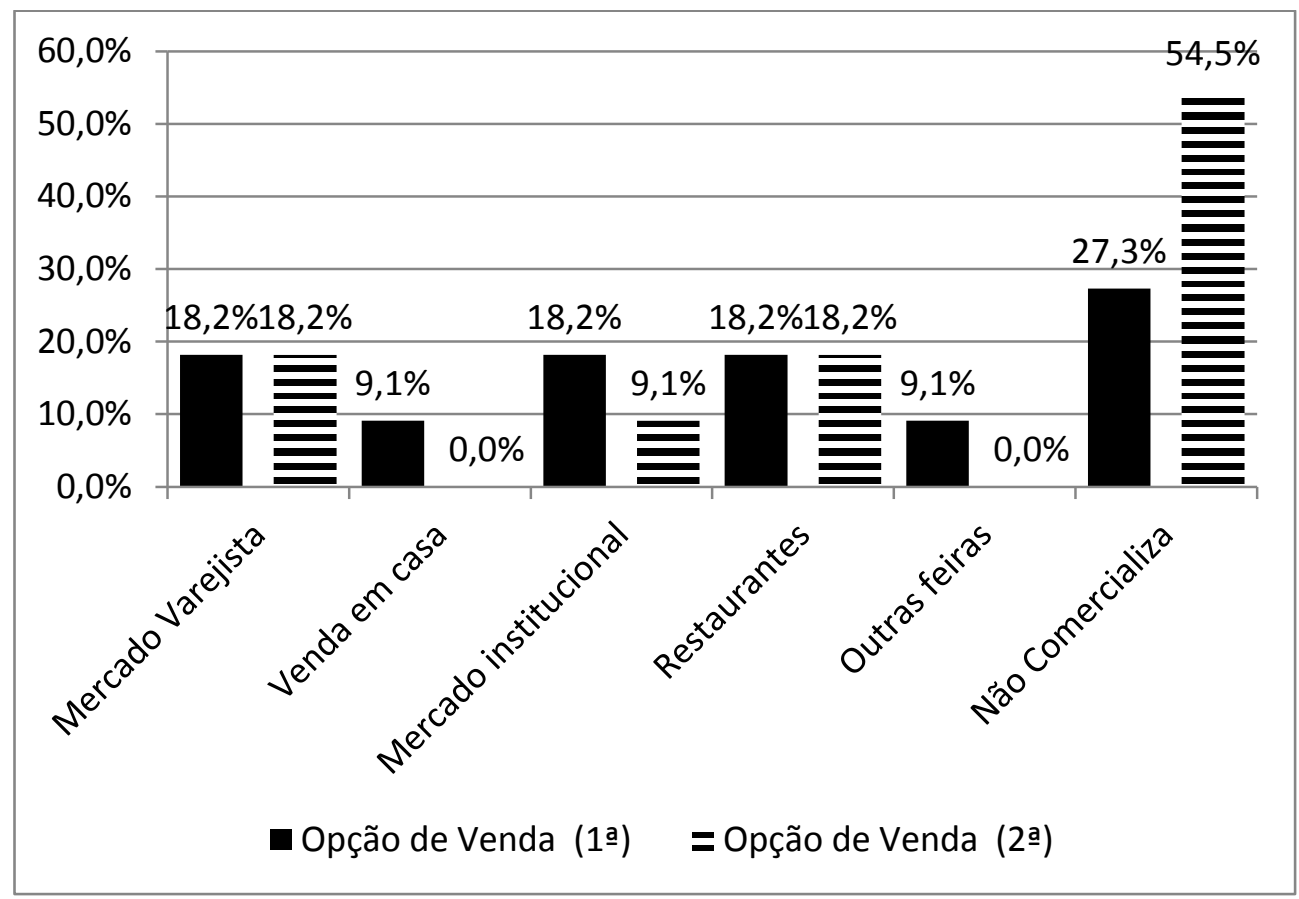


são mediadas entre agricultores e consumidores em interação direta, 18,2\% participam em outras feiras da região ou realizam vendas a domicílios em São Pedro do Sul. A feira livre se mantem como opção mais importante de comercialização, mas isso não impede que exista comercialização em feiras regionais ou diretamente na casa dos consumidores. Já em Santo Augusto, a comercialização face a face pela venda a domicílios acontece com $14,3 \%$ dos feirantes, tanto em primeira como em segunda opção de venda.

Além dos mercados face a face, também ampliam a gama de oportunidades para os agricultores, as formas de participação nos mercados dentro do que Renting, Marsden e Banks (2003), denominam de mercados a partir de relações de proximidade. Para os autores, nesses casos, a relação está baseada na proximidade espacial, em que os produtos são vendidos na região de produção, e os consumidores estão cientes da natureza local do produto no ponto de varejo. A forma mais representativa é a comercialização para mercados varejistas, em que 71,4\% dos feirantes de Santo Augusto utilizam como primeira opção depois da feira livre. Já no caso de São Pedro do Sul esse número corresponde a $18,2 \%$ dos feirantes como primeira opção de comercialização e 18,2\% como segunda, conforme apontam os resultados evidenciados pelo gráfico 01. Outra parte da produção é comercializada para restaurantes locais, sendo que em São Pedro do Sul 18,2\% comercializa como primeira opção e 18,2\% como segunda opção.

No caso de Santo Augusto esses valores também são ratificados, como demonstra o gráfico 02 , porém com $14,3 \%$ como primeira opção e 42,9\% como segunda opção. Os mercados institucionais também fazem parte destas formas de comercialização, sendo em proporção inferior ao comercializado através de outras formas. No caso de São Pedro do Sul 18,2\% comercializam em primeira opção e 9,1\% em segunda opção. Já no caso de Santo Augusto esse número reduz para $14,3 \%$.

Mesmo considerando que os mercados institucionais tem se mostrado iniciativas importantes de integrar as cadeias relacionadas a agricultura familiar, os feirantes não participam ativamente desses mercados. As estratégias que criam obrigações contratuais com os compradores podem ser tratadas como um elemento que de certa maneira obriga os agricultores ao cumprimento. Como a atividade agrícola é condicionada por fatores climáticos e biológicos, que deixa a produção em uma condição indefinida, acaba estabelecendo e favorecendo a formação de outras pequenas redes de comercialização e abastecimento local, tal como a compra por restaurantes, mediadas por relações diretas e informais.

Quando relacionado à satisfação do preço praticado nas feiras livres com as diferentes formas

Gráfico 02: Opções de comercialização dos Feirantes de Santo Augusto (RS), em outros canais de cadeia curta após a participação na feira livre (\%).

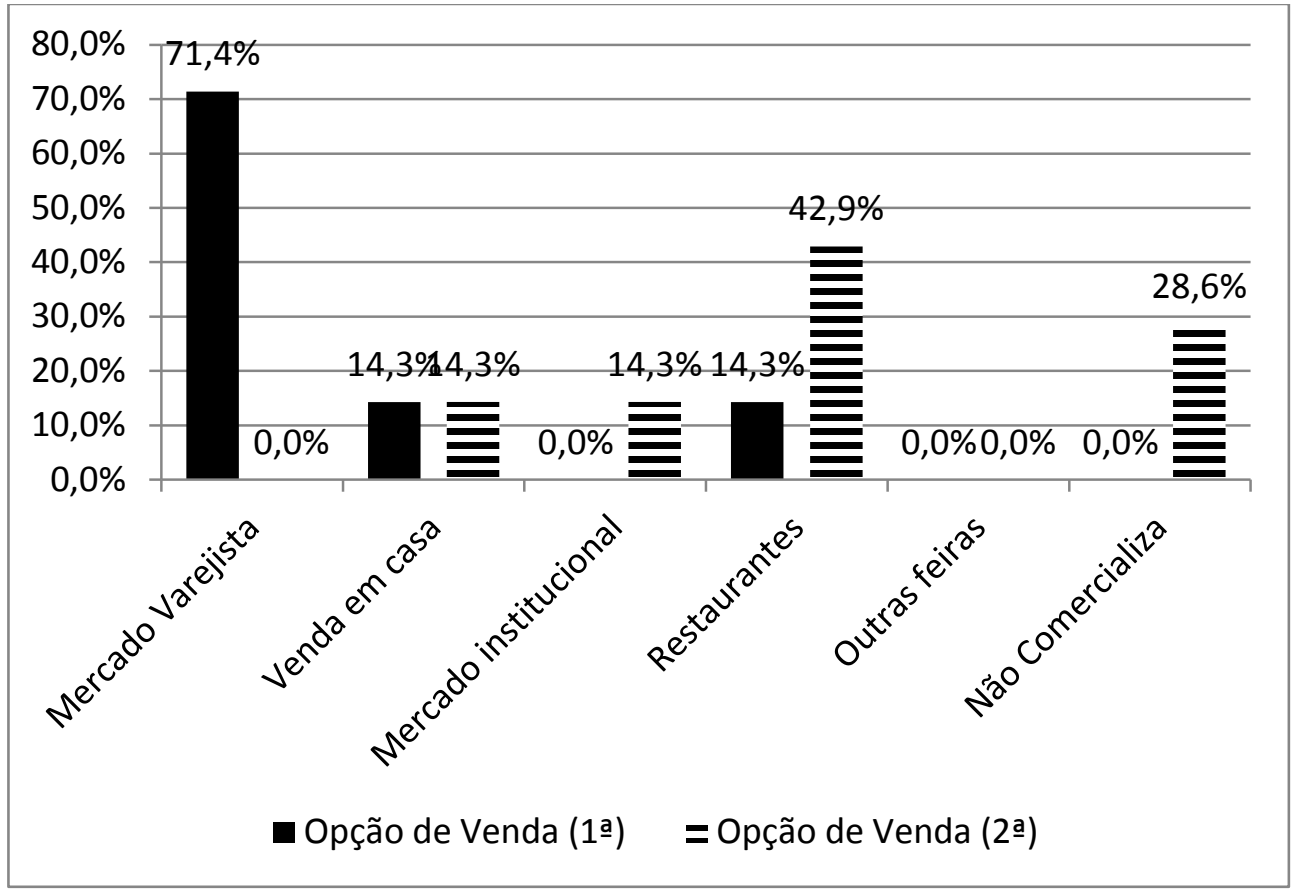


de participação nos mercados, não se verifica diferença estatística em função das opções de mercado. A maior concentração na forma de mercados varejistas pode ser um fator que explique a maior insatisfação dos agricultores de Santo Augusto em relação aos preços praticados na feira-livre, pois $71,4 \%$ consideram o preço baixo e $28,6 \%$ o preço justo. Em São Pedro do Sul, onde a maior parte das relações com os mercados acontecem em relações face a face, a satisfação com o preço, considerado como justo ou bom é de $90,9 \%$.

Esse conjunto de interações com os mercados denotam estratégias complementares de abastecimento, advindas em função de aspectos diferenciados dos alimentos em relação àqueles obtidos pelo mercado de massa. Porém, todos eles mantêm os aspectos básicos da cadeia curta de abastecimento, principalmente de construção das formas de comercialização a partir das demandas existentes. De acordo com Renting, Marsden e Banks (2003), o acesso aos mercados é cada vez mais condicionado pela capacidade de atender a critérios específicos, variedade, aparência dos produtos, práticas de rotulagem e capacidade de entrega flexível. A participação de um conjunto de estratégias para além da feira livre não denota competitividade entre si, mas que advém justamente como resultado das interações com os consumidores e as demandas locais. A feira é um espaço de aprendizado, de reforço em aspectos de procedência, pertencimento territorial, dentre outros que denotam valorização da produção local.

Segundo Morgan (2010), se o alimento é fundamental para o desenvolvimento humano do ponto de vista fisiológico, é também um veículo importante para a identidade cultural e o desenvolvimento econômico. Essas expressões encontradas estão de acordo com Wiskerke (2010), por representar redes vinculadas entre consumidores e o mercado de alimentos, reconectando a comida ao contexto local, contribuindo para a regionalização da economia alimentar, criando sinergias com os domínios públicos, baseadas nas especificidades regionais, normas sociais, tradições, dentre outros.

\subsection{As percepções dos feirantes sobre a feira e sobre sua auto avaliação como feirante.}

Entre os objetivos deste trabalho também buscou-se a compreensão de como os feirantes avaliam a condição geral das feiras livres como espaços de comercialização, bem como sua própria auto-avaliação no que se refere a condição de ser feirante. Para tanto, foram elaborados questões para que os entrevistados atribuíssem graus de concordância, conforme a escala de Likert, os quais variavam de 1 a 5 , sendo 1 a opção de totalmente inadequado e 5 a opção de totalmente adequado.

Os atributos de localização e horário da feira foram os que apresentaram maior frequência em São Pedro do Sul na pontuação 5, e os atributos dia de realização e horário em Santo Augusto (Tabela 04). Pela classificação das médias dos atributos, o dia de realização da feira em São Pedro do Sul, e respectivamente a localização da feira e a apresentação geral em Santo Augusto, são fatores que se apresentam como oportunidades de melhoria. Por meio do teste ANOVA, foi possível identificar que a idade dos feirantes e o tempo de participação da feira não interferem estatisticamente a um nível de significância de $5 \%$ sob a importância de nenhum dos itens relacionados.

Os atributos de atendimento aos consumidores e regularidade de oferta são os que apresentaram maior frequência na pontuação 5 em São Pedro do Sul, corroborado também pela classificação das médias (Tabela 5). Já em

Tabela 04: Importância dos atributos em relação à condição geral de realização das Feiras Livre nos municípios de São Pedro do Sul e Santo Augusto (RS).

\begin{tabular}{|c|c|c|c|c|c|c|c|c|c|c|c|c|}
\hline \multirow[t]{2}{*}{ Variável } & \multicolumn{6}{|c|}{$\begin{array}{l}\text { São Pedro do Sul } \\
\text { Grau de concordância (\%) }\end{array}$} & \multicolumn{6}{|c|}{$\begin{array}{l}\text { Santo Augusto } \\
\text { Grau de concordância (\%) }\end{array}$} \\
\hline & 1 & 2 & 3 & 4 & 5 & Média & 1 & 2 & 3 & 4 & 5 & Média \\
\hline Localização & - & - & - & - & 100,0 & 5,00 & $\begin{array}{c}28 \\
6\end{array}$ & 28,6 & - & - & 42,9 & 3,00 \\
\hline Apresentação Geral & - & - & 9,1 & $\begin{array}{c}36 \\
4\end{array}$ & 54,5 & 4,45 & - & 42,9 & - & 42,9 & 14,3 & 3,28 \\
\hline Dia de realização & - & - & 27,3 & $\begin{array}{c}27, \\
3\end{array}$ & 45,5 & 4,18 & - & 14,3 & 14,3 & - & 71,4 & 4,28 \\
\hline Horário & - & - & 18,2 & 9,1 & 72,7 & 4,54 & - & - & - & - & 100 & 5,00 \\
\hline
\end{tabular}


Tabela 05: Importância dos atributos em relação ao preparo dos feirantes para a realização das Feiras - Livre nos municípios de São Pedro do Sul e Santo Augusto (RS).

\begin{tabular}{lcccccc|cccccc} 
& \multicolumn{9}{c|}{ Grau de concordância $(\%)$} & \multicolumn{4}{c}{ Grau de concordância (\%) } \\
& 1 & 2 & 3 & 4 & 5 & Média & 1 & 2 & 3 & 4 & 5 & Média \\
\hline Regularidade & - & - & 11,1 & 33,3 & 55,6 & 4,44 & - & 14,3 & - & 14,3 & 71,4 & 4,42 \\
Vestimentas & - & 9,1 & 54,5 & 27,3 & 9,1 & 3,36 & - & 14,3 & - & 14,3 & 71,4 & 4,42 \\
Higiene & - & - & 44,4 & 11,1 & 44,4 & 4,00 & - & 42,9 & - & 28,6 & 28,6 & 3,43 \\
Atendimento & - & - & 9,1 & 27,3 & 63,6 & 4,54 & 14,3 & 14,3 & - & 14,3 & 57,1 & 3,85 \\
\hline
\end{tabular}

Santo Augusto, além desses atributos, também tem predominância a vestimenta utilizada pelos agricultores, que recebe a menor média em São Pedro do Sul. Os feirantes de Santo Augusto consideram como o fator mais precário de sua participação nas feiras a higiene na manipulação dos alimentos na comercialização. Através do teste ANOVA, foi possível identificar que a idade dos feirantes interfere estatisticamente a um nível de significância de $5 \%$ sob o grau de importância da higiene na manipulação de alimentos no decorrer da feira. Por outro lado, o tempo de participação na feira não tem interferência sobre o grau em que atribui importância a todos os itens.

\section{CONCLUSÕES}

As feiras dos municípios de São Pedro do Sul (RS) e Santo Augusto (RS) possuem similitudes no aspecto organizacional, sendo a característica de serem empreendimentos familiares a mais forte. Predominam o uso de mão de obra da família e uso de terras próprias entre os feirantes. A família é importante também na comercialização, pois mesmo nos casos em que há contratação de mãode-obra, ela é sempre exclusividade dos membros da família, fato que nas cadeias curtas de abastecimento tem uma importância considerável. Diante dessa característica, acentua-se a ameaça advinda das dificuldades de sucessão que as famílias feirantes já manifestam.

Evidencia-se que esse grupo apresenta limitações no tocante à formação escolar, fato que talvez necessite de maiores estudos, mas certamente dificulta o aprendizado e a inovação em suas propriedades. Dada a característica intensiva da produção e o envolvimento de tempo considerável na comercialização (que não envolve apenas o tempo efetivo de feira, mas a colheita, lavagem e embalagem dos produtos) e o esforço físico que é necessário nessas atividades, fica difícil imaginar que esse déficit de escolaridade se resolve pela oferta de cursos na forma regular e nos estabelecimentos de ensino. Nesse contexto, a assistência técnica e extensão rural, assim como no início das feiras, e talvez, outras formas de qualificação profissional como o Pronatec (Programa Nacional de acesso ao Ensino Técnico e Emprego), ou modalidades de ensino com o uso de Tecnologias de Informação possam ser alternativas para enfrentar o problema.

A participação dos feirantes em outras formas de cadeia curta de abastecimento indica que as feiras podem ser uma etapa inicial para os agricultores adquirirem aprendizado. Isso permite o acesso a outras formas, ampliando a produção, aumentando a renda e gerando alternativas para o abastecimento local. Assim, as feiras representam uma boa iniciativa do ponto de vista do desenvolvimento local e regional, contribuindo com a diversificação e a melhoria na oferta de alimentos. Ao analisar a participação dos agricultores em mercados institucionais, quando na presença de outros mercados de cadeia curta, os feirantes não se mostram aderentes.

Efetivamente, pode afirmar que a feira é um espaço para tirar o agricultor do anonimato, ampliando suas oportunidades e capacidade de negociar e, que contribui para construir a sua relação com o abastecimento local. De outro lado cada uma das feiras apresentam características bem próprias aos seus contextos, e que contrastam também com percepções diferentes entre agricultores em relação a como a feira é compreendida para a construção dos mercados de cadeias curtas de abastecimento. Isso denota que pensar essas atividades demanda compreender os contextos nos quais se encontram inseridas, sob o risco de deixar de dar atenção aos processos e dinâmicas locais de desenvolvimento. 


\section{REFERENCIAS}

BRUNI, A. L. SPSS Guia Prático para Pesquisadores. São Paulo: Atlas, 2012. 280 p.

DALFOVO, M. S. et al. Métodos quantitativos e qualitativos: um resgate teórico. Revista Interdisciplinar Científica Aplicada, Blumenau, v.2, n.4, p.0113, Sem II. 2008

GIL, A. C. Métodos e técnicas de pesquisa social. São Paulo: Atlas, 2009.

GOODMAN, D. The quality 'turn' and alternative food practices: reflections and agenda. Journal of Rural Studies, v. 19, p.1-7, 2003.

ILBERY, B.. Product, Process and Place: An Examination of Food Marketing and Labelling Schemes in Europe and North America. European Urban and Regional Studies, vol 12(2), 2005. p.116-132. Disponível em <http://www.sagepub.com/mcdonaldizationstudy5/articles/Food_Articles\%20PDFs/Ilbery. pdf $>$. Acesso em 20 de ago. 2013.

MARSDEN, T.; BANKS, J; BRISTOW. G. Food supply chain approaches: exploring their role in rural development. In.: Sociologia Ruralis, vol 40. N. 4. October, 2000. Disponível em <http://onlinelibrary. wiley.com/doi/10.1111/1467-9523.00158/pdf>. Acesso em 10 set. 2013.

MAZOYER, M., ROUDART, L. História das agriculturas no mundo: do neolítico à crise contemporânea [tradução de Cláudia F. Falluh Balduino Ferreira]. - São Paulo: Editora UNESP; Brasília, DF: NEAD, 2010.

MORGAN, K.J. (2010) Local and Green, Global and Fair: The Ethical Foodscape and the Politics of Care. Environment and Planning A, 42(8). p. $1852-$ 1867.

PALM, J, L. Agroindústrias familiares e Feira Livre dos Produtores rurais de Teutônia-RS (1985-2011): estruturação de alternativas de mercantilização da agricultura familiar em meio ao predomínio da integração a grandes agroindústrias. In: CONTERATO, M. A. et al (orgs). Mercados e agricultura familiar: interfaces, conexões e conflitos. Porto Alegre: Via Sapiens, 2013. p. $78-98$.

PESAVENTO, S. J. História do Rio Grande do Sul. Porto Alegre: Mercado Aberto, 1992.
POUPART, J. A entrevista de tipo qualitativo: considerações epistemológicas, teóricas e metodológicas. In.: POUPART, J. et al (org.). A pesquisa qualitativa: enfoques epistemológicos e metodológicos. Petrópolis: Vozes, 2010. p. $215-253$.

RENTING, H., MARSDEN, T. K., BANKS, J. Understanding alternative food networks: exploring the role of short food supply chains in rural development. In.: Environment and Planning A. 2003, volume 35 , p. 393-411.

SABOURIN, E. Sociedades e Organizações Camponesas: uma leitura através da reciprocidade. Porto Alegre: Editora da UFRGS, 2011. 270 p.

WILKINSON, J. Mercados, redes e valores. Porto Alegre: UFRGS Editora, 2008. 213 p.

WISKERKE, J.S.C. On places lost and places regained: reflections on the alternative food geography and sustainable regional development. International Planning Studies, 2010. 